\title{
PM MOTORS FOR HIgH EFFICIENCY APPLICATIONS
}

\section{Abstract}

PM motors are suitable for nearly all applications, like pumps, elevators, compressors, blowers, extruders, generators, electric vehicles, servodrives, cooling towers, household appliances, etc. This paper will present some applications where the use of PM motors allowed for enhancements in energy efficiency and process quality.

\section{Introduction}

According to recent studies [1], electric motor-driven systems (EMDS) account for between $43 \%$ and $46 \%$ of all global electricity consumption.

Induction motors have been the most used drives in industry, due to its robustness, reliability and simple operation (direct connection to the mains, without electronic control). However, in many applications variablespeed drives offer significant energy saving potential [2]. In this scenario, permanent magnet motors are competing technologies for the induction motors, because they present higher efficiency and do not need forced ventilation neither over sizing.

\section{Permanent Magnet Motors}

PM motors offer the highest efficiency of all motors, due to the absence of joule losses in the rotor, and high power factor due to the excitation flux of the permanent magnets (resulting in smaller currents). Since PM motors have no Joule losses in the rotor, bearing temperature is lower, and lifetime is increased.

They have a significant higher efficiency at low speeds than the induction motors and do not need forced ventilation, neither over sizing for constant torque operation (rated torque in all speeds).
Figure 1 shows a comparison among an IPM motor (IE4 +) and two induction motors (IE2 and IE3), all rated $30 \mathrm{~kW}$ at $1800 \mathrm{rpm}$, operating over a 4:1 speed range with constant rated torque.

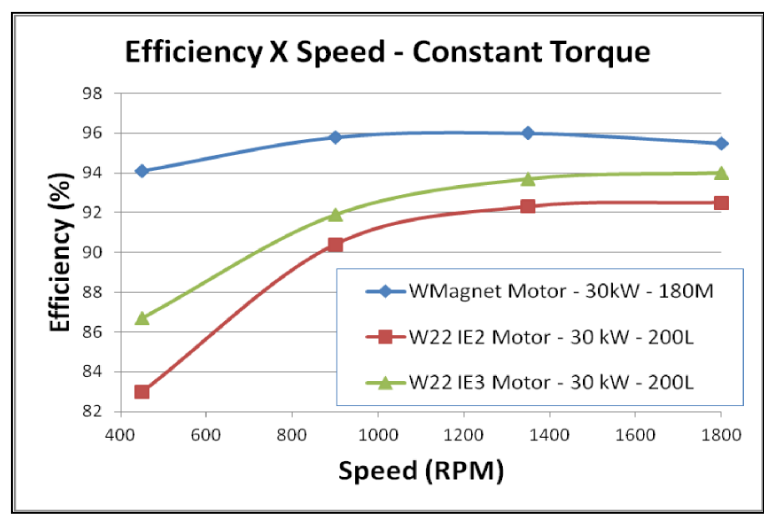

Figure 1. Efficiency over a 4:1 speed range with constant torque for three motors: a PM synchronous motor (Wmagnet), and two induction motors (W22 IE2 and W22 IE3), all rated $30 \mathrm{~kW}$ at $1800 \mathrm{rpm}$

\section{Construction Characteristics}

PM motors can have different construction characteristics.

The permanent magnets can be placed on the surface or inside the rotor (IPM - Interior Permanent Magnet), the rotor can be external or internal, the windings can be distributed (as for conventional induction motors) or toothwound (as in universal motors). They can use low-cost, lowenergy ferrite magnets (usually for low-power, low-cost applications) or high-cost, high-energy rare-earth magnets (usually for high performance motors in industrial applications), resulting in more compact designs with high torque/volume ratios.

Furthermore, they can be classified as BLAC (Brushless Alternating Current) or BLDC (Brushless Direct Current) motors. The first use a sine wave current drive (their backEMF is sinusoidal) and the latter use a square wave current 
drive (their back-EMF is trapezoidal). Typically, BLDC motors have tooth-wound windings, and BLAC motors have distributed windings. But BLAC motor can have toothwound windings as well, mainly for low-power applications.

There are several topologies, and the applicability of each one depends on the application requirements, as shown in the table 1.

\section{Applications for PM Motors}

\subsection{Industrial PM Motors}

\subsubsection{IPM Motor}

IPM synchronous motors have similar stator windings as induction motors, but have high-energy rare-earth magnets inside the rotor.
Figure 2 shows a detail of a one-pole finite element simulation of a 6-pole IPM motor on load. The rotor has a special designed lamination to minimize flux leakage while keeping the necessary mechanical strength at the higher speed allowed.

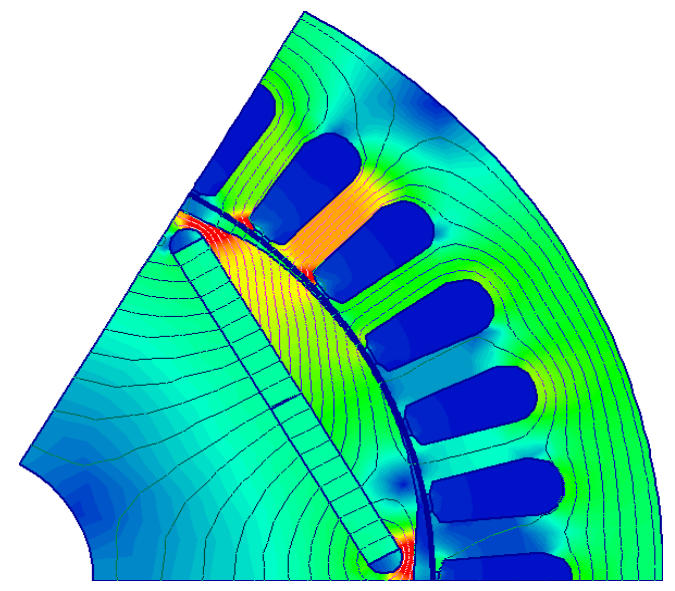

Figure 2. Detail of one pole flux pattern and flux density of a 6-pole IPM motor

Table1. Characteristics of different topologies

\begin{tabular}{|c|c|c|}
\hline Topology & Characteristics & Example \\
\hline External rotor & $\begin{array}{l}\text { high-torque, low-speed } \\
\text { applications (i.e. } \\
\text { washing machine, } \\
\text { elevators), ventilation, } \\
\text { wheel motors for traction } \\
\text { applications. }\end{array}$ & \\
\hline $\begin{array}{c}\text { Surface } \\
\text { magnets }\end{array}$ & $\begin{array}{l}\text { low-speed applications } \\
\text { (i.e. ventilation, } \\
\text { exhaustion, residential } \\
\text { pumps, elevators). }\end{array}$ & \\
\hline Interior magnets & $\begin{array}{l}\text { low and high-speed } \\
\text { applications (i.e. } \\
\text { blowers, compressors, } \\
\text { pumps, elevators, } \\
\text { electric vehicles). }\end{array}$ & \\
\hline Line-start & $\begin{array}{l}\text { low-speed, low-inertia } \\
\text { applications, direct-on- } \\
\text { line connection (i.e. } \\
\text { small fans, pumps) }\end{array}$ & \\
\hline
\end{tabular}


These motors can be one frame size smaller than induction motors (up to $43 \%$ reduction in volume and $35 \%$ in weight), while offering super premium efficiencies (Figure 3) [3].
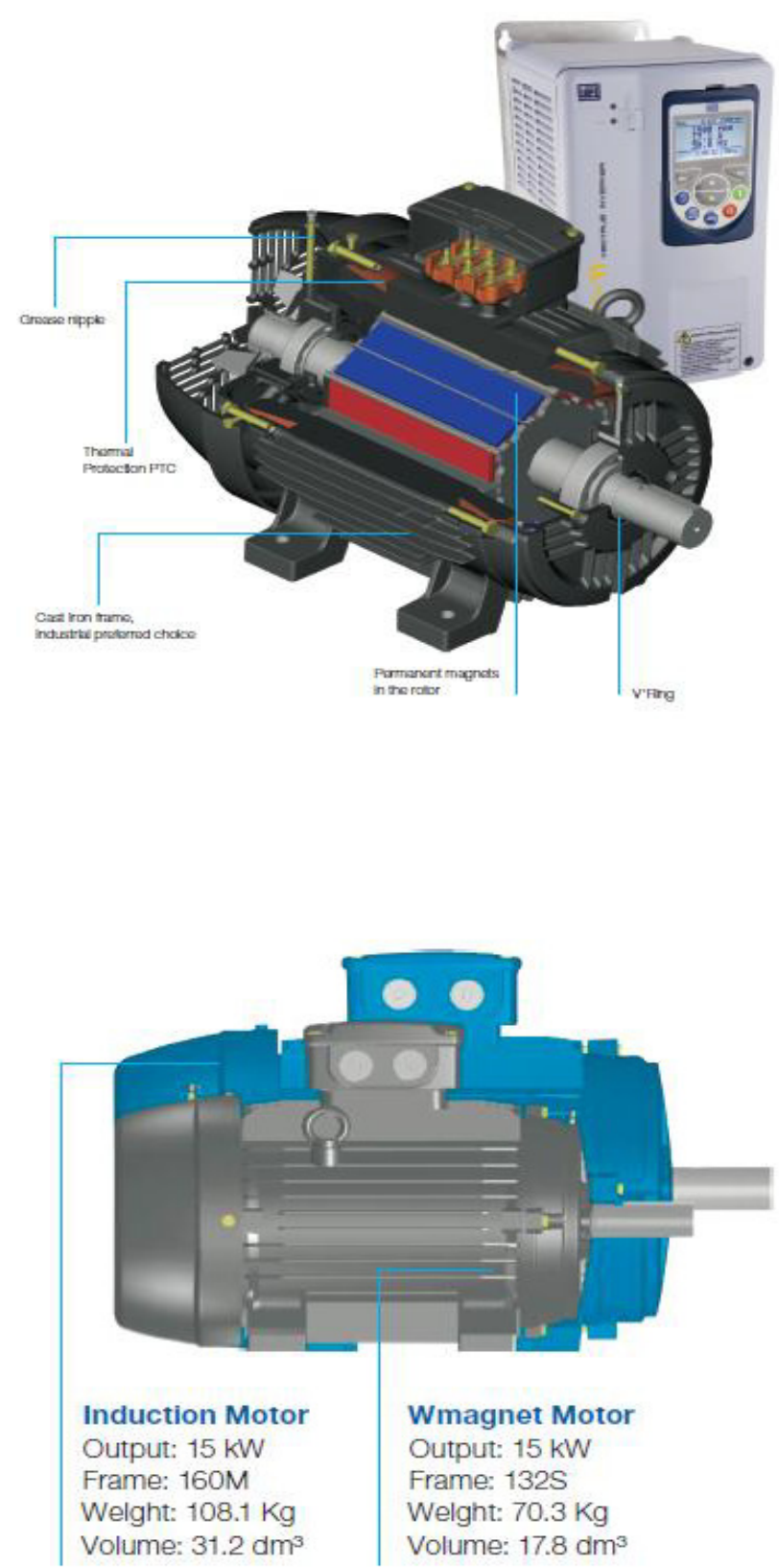

Figure 3. Interior permanent magnet motor with rare-earth magnets and reduced frame size

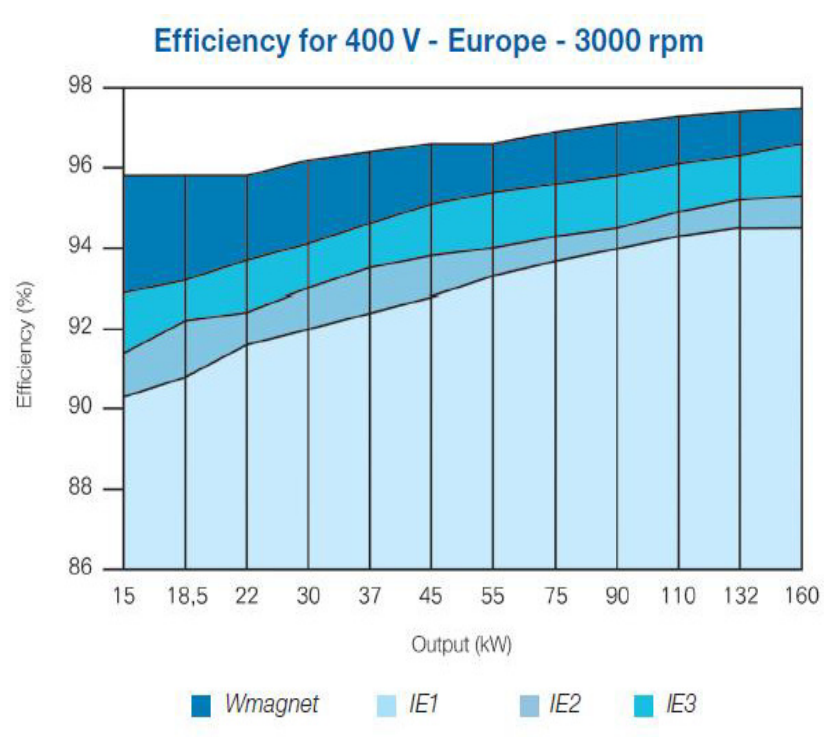

Figure 3a. Efficiency comparison between IPM synchronous motors and IEC efficiency levels

Since they are in a reduced size frame, they have lower noise levels than induction motor of the same output power.

The main applications are pumps, ventilation systems, compressors, wire drawing machines, extruders and conveyor belts.

\subsubsection{Line-start PM Motor}

These motors are hybrid motors because they have rareearth magnets below the squirrel-cage [4]. They have similar windings as induction motors and have the ability to start direct on line, without the need for electronic controller. They start and accelerate like an induction motor, until synchronism is achieved, keeping constant speed with varying load, with super premium efficiency.

Figure 4 shows an example of a 6-pole line-stating motor lamination. The stator has the same lamination as the induction motor counterpart. The rotor lamination has especially designed aluminum bars and slots for permanent magnets to allow good starting capabilities (starting torque and synchronization) and good synchronous operation (high pull-out torque and high efficiency). 


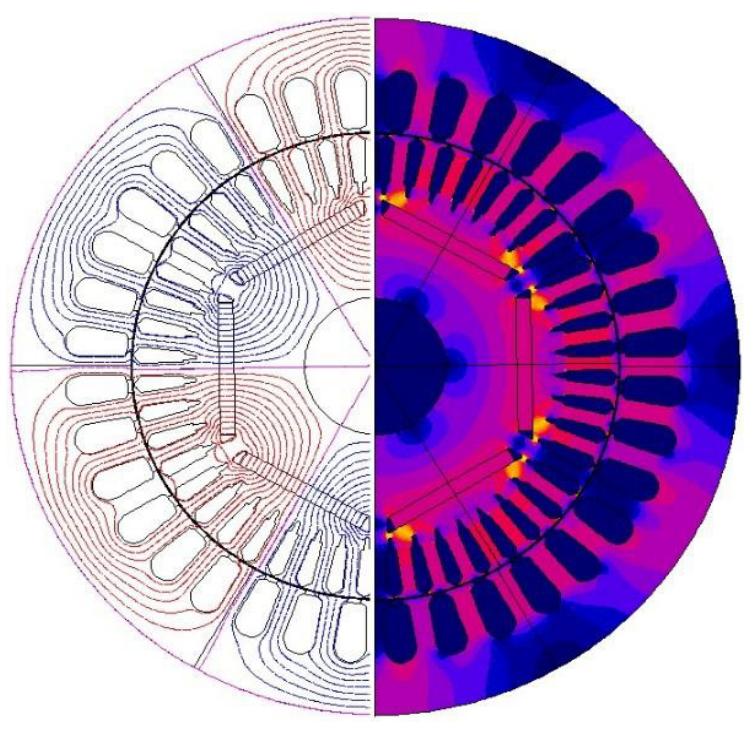

Figure 4. Example of a 6-pole line-start motor showing flux pattern and flux density

If variable speed is needed, they can be driven by a conventional frequency inverter, in scalar mode. This allows several motors to be driven by the same inverter, running at the same speed.

Figure 5 shows the efficiency levels compared to IEC levels.

Efficiency - 4 poles - $50 \mathrm{~Hz}$ - IEC

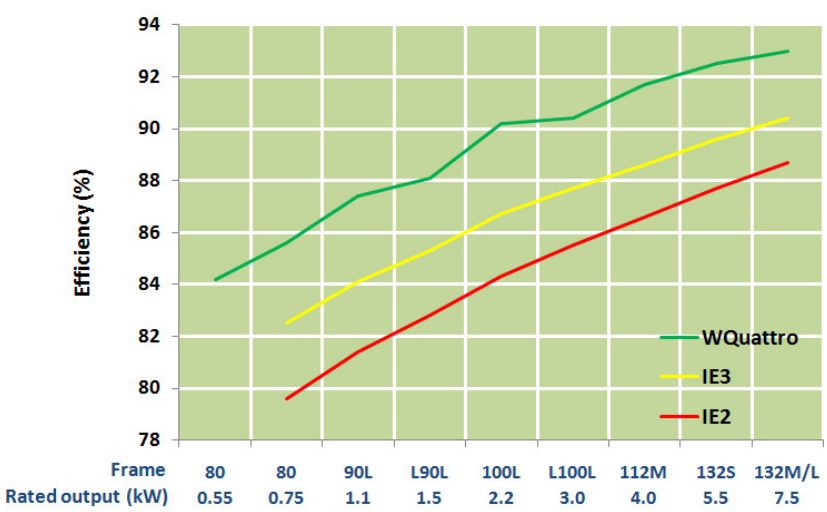

Figure 5. Efficiency comparison between Line-start PM motors and IEC efficiency levels
The main applications are low-inertia loads (up to 30 times de rotor inertia), and multi-motor variable-speed with one single inverter. The inertia of the load is an important issue, because if it is greater than the limit value, the motor shall fail to synchronize, and will operate at a speed below synchronous speed, having high currents, noise and vibration, and the motor must not operate in this condition.

Multi-motor variable-speed applications with on inverter can be an economic solution for those applications that need that several motors work in the very same speed.

\subsection{Application in compressor}

A PM motor was used in substitution of an induction motor in a 200 HP screw compressor (Figure 6).

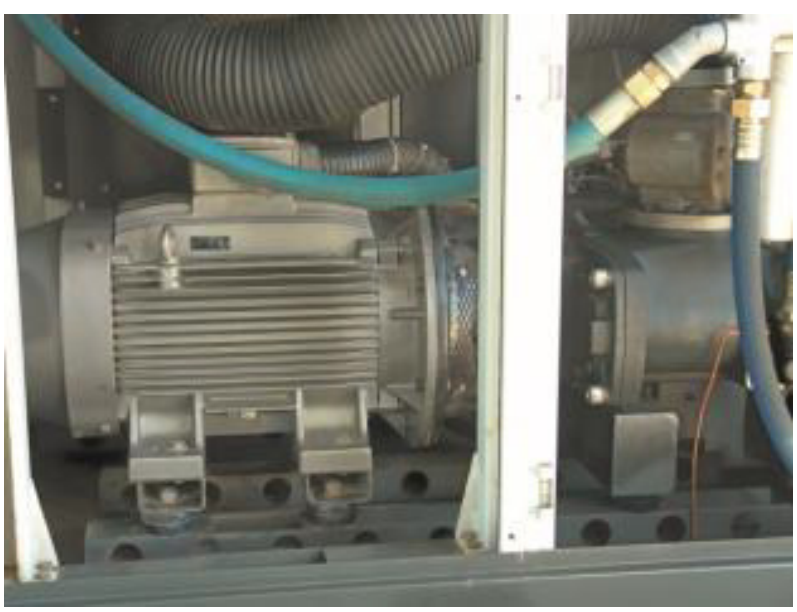

Figure 6. Compressor with PM motor

Figure 7 shows the efficiency comparison of the compressor over its speed range when using an induction motor and when using a PM motor.

The induction motor was rated $150 \mathrm{~kW}, 2$ poles, IEC frame $280 \mathrm{~S} / \mathrm{M}$. The PM motor was rated 150kW, $3600 \mathrm{rpm}$, IEC frame 250 S/M PM motor. There has been a significant increase in efficiency by the use of the PM motor. Also, the PM motor is one frame size smaller, with $52 \%$ of the weight of the induction motor. 
$3600 \mathrm{rpm}$ (of the compressor)

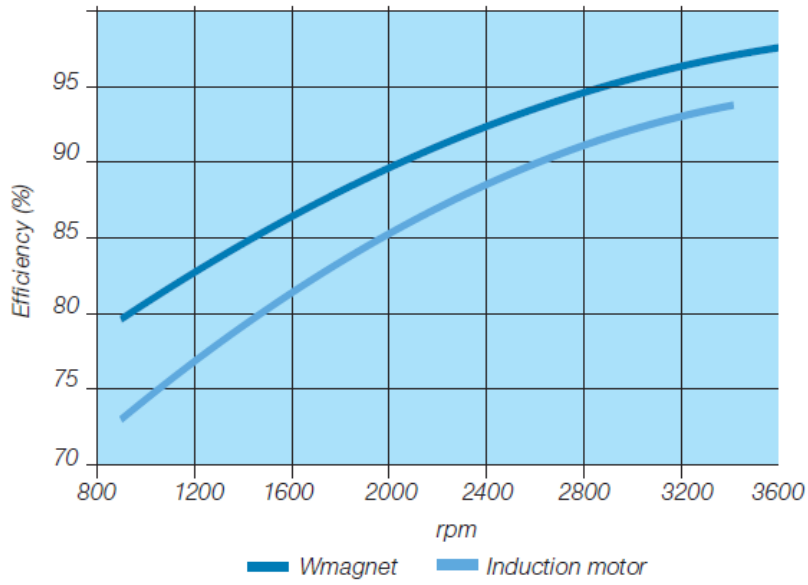

Figure 7. Efficiency of the compressor with IPM motor and induction motor

\subsection{Application in wire drawing machine}

A $100 \mathrm{HP}, 4$ poles, IEC frame $250 \mathrm{~S} / \mathrm{M}$ Induction motor was substituted by a $100 \mathrm{HP}, 1500 \mathrm{rpm}$, IEC frame $225 \mathrm{~S} / \mathrm{M}$ PM motor in a wire drawing machine (Figure 8).

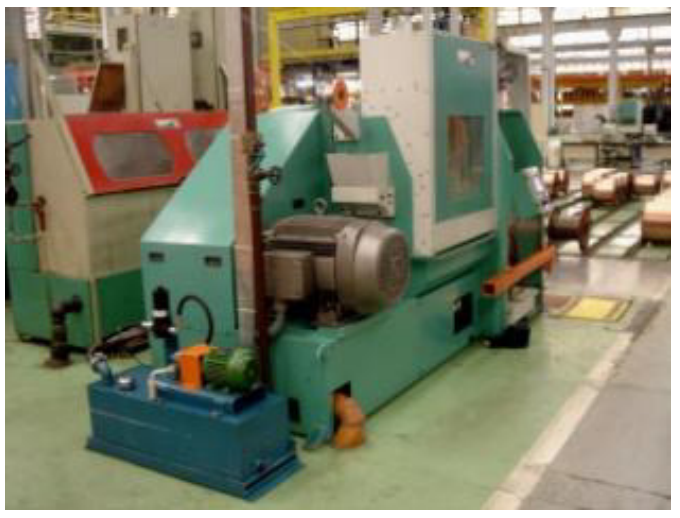

Figure 8. Wire drawing machine with PM motor

This change allowed average energy savings of $3.9 \%$ in the operation cycle of the machine, corresponding to a monthly saving of $720 \mathrm{kWh}$ considering continuous operation; an increase in the wire production range (lower speed with increased load torque), because the PM motor works cooler than the original induction motor; and the temperature of the bearings was greatly reduced, allowing a longer useful life of the bearings, longer lubrication intervals, and less maintenance.

\subsection{Application in textile industry}

The original motor of the yarn starching machine (Figure 9) was a ring induction motor, which had brushes that needed to be replaced regularly and demanded constant maintenance. When this motor burnt and needed to be repaired, the decision to seek a more efficient alternative led to the choice of a PM motor. The cost to fix the old motor would be $115 \%$ of the amount to acquire a new and more efficient motor. So, the new motor chosen was a $15 \mathrm{~kW}$ PM motor. The replacement reduced the maintenance costs (practically zero) and shutdown hours of the machine, and enhanced the process with speed variation with constant torque (which means saving energy) and more power in the operation. It also brought more versatility to speed control which is essential for the quality of the starching, a process prior to the production of fabric. The PM motor is $50 \%$ smaller than the original motor. This calls for less space and makes eventual maintenance easier.

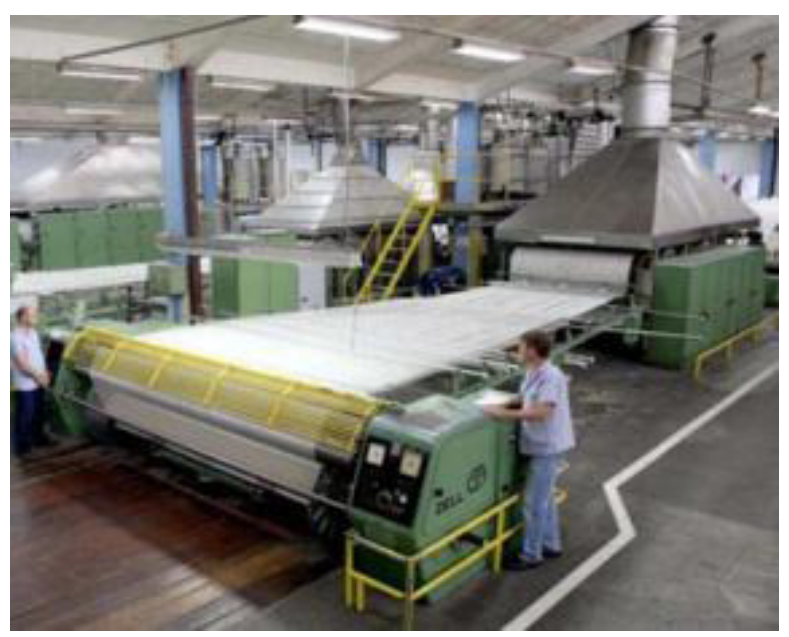

Figure 9. Textile machine

\subsection{Application in cooling tower}

PM motors for cooling towers use rare-earth magnets and have a high number of poles, producing high torque at low speeds, for direct-drive coupling (Figure 10). This eliminates gear-boxes, leading to less maintenance and less mechanical losses, that together with the lower electrical losses of the PM motor, increases the overall efficiency of the system. 


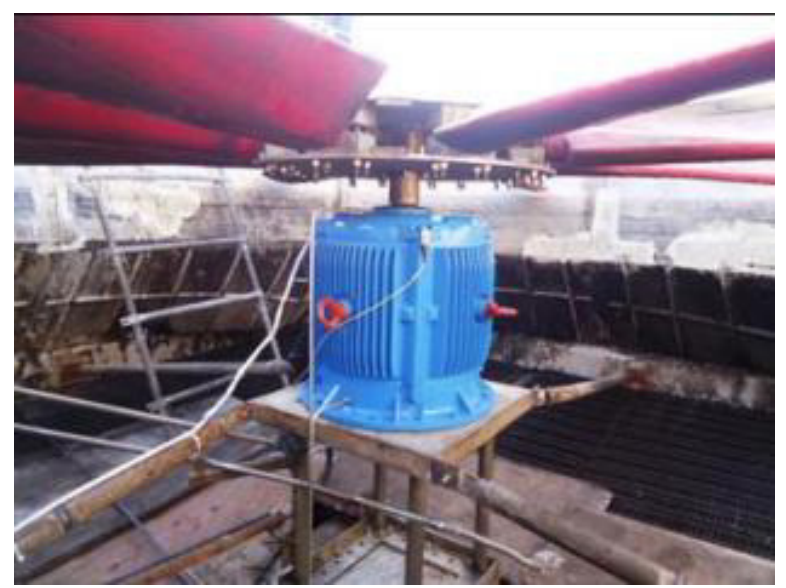

Figure 10. Cooling tower with PM motor

\subsection{Application in extrusion machine}

The volume of plastic material that is extruded depends on the rotational speed of the helical thread. Extrusion machines demand constant speed of the helical thread to assure the quality of the process. Also, different materials require different speeds. DC and induction motors with magnetic clutch are commonly used in these machines, but the maintenance of these motors is costly and frequent. Also induction motors with frequency inverters are used.

A PM motor was applied in an extrusion machine (Figure 11), which used a DC motor. Annual energy savings of $21 \%$ were obtained. Besides the higher efficiency, the PM motor offers other advantages like low maintenance (less shutdown time machine), no necessity for forced ventilation and constant torque at low speeds.

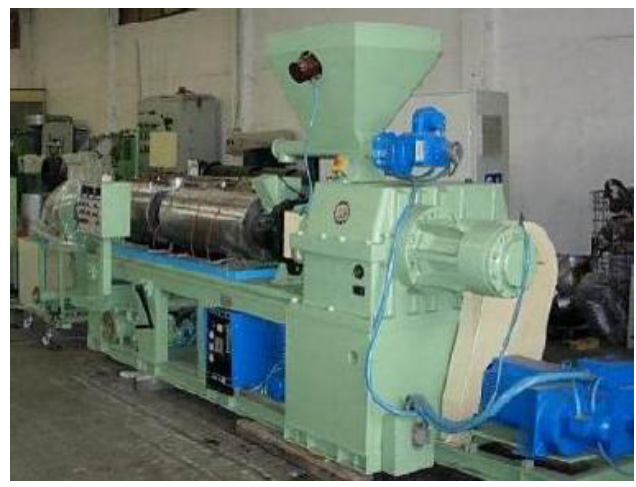

Figure 11. Extrusion machine with PM motor

\section{Conclusion}

PM motors can have different construction characteristics, to meet different application requirements. Due to their higher efficiency compared to induction motors, PM motors present a significant reduction in energy consumption in all the applications shown in this paper.

Moreover, in variable speed applications, PM motors are even more advantageous, because they do not need forced ventilation nor over sizing for constant torque operation, and as the speed decreases, the efficiency decreases less than it does for induction motors.

It should also be emphasized that for industrial applications rare-earth PM motors are usually one frame size smaller than the induction motor counterparts. This leads to a reduced volume and weight, and lower noise and vibration level. Since the motor operates cooler because there are no Joule losses in the rotor, bearing temperature is lower, and life time is increased.

\section{References}

[1] P. Waide, C. U. Brunner, "Energy-Efficiency Policy Opportunities for Electric Motor-Driven Systems", International Energy Agency (IEA), 2011.

[2] A. T. de Almeida, F. J. T. E. Ferreira, D. Both, "Technical and Economical Considerations in the Application of Variable-Speed Drives With Electric Motor Systems", IEEE Transactions on Industry Applications, Vol. 41, No. 1, Jan/Feb 2005.

[3] Wmagnet Drive System Catalogue, http://ecatalog.weg.net/files/wegnet/WEG-wmagnetdrive-system-50020762-brochure-english.pdf

[4] WQuattro Catalogue, http://ecatalog.weg.net/files/wegnet/WEG-wquattroeuropean-market-50025713-brochure-english.pdf 